\title{
Role of natural terroir attributes on Barbera grapevine performance and grape quality in Piemonte region (Italy)
}

\author{
Gonzalez Perez Laura Alexandra ${ }^{1}$, Bavaresco Luigi ${ }^{2}$ and Etienne Neethling ${ }^{1}$ \\ ${ }^{1}$ ESA, International Vintage Master, Department of Viticulture and Oenology, Ecole Supérieure d'Agricultures, \\ Angers 49007, France \\ ${ }^{2}$ UCSC, Department of Sustainable Crop Production, Pomology and Viticulture section, Università Cattolica del Sacro \\ Cuore, Piacenza 29211, Italy
}

\begin{abstract}
The trial was carried out in the Bersano estate (Nizza Monferrato, Piemonte, Italy) in different vineyards (Generala, Cremosina and Monteolivo) devoted to the production of DOCG Nizza, the newest and highly reputed Barbera denomination. For Bersano, this research provided access to scientific information and tools to valorise its Nizza wines and to characterize and select some sub-zones. The study investigated the effect of natural terroir attributes on vine behaviour and grape composition of cv. Barbera. Conducted in 2017, the tests included phenological phases, vegetative growth, chlorophyll and gas exchange measures. Maturation curves were also developed to better understand the time course of berry ripening, from fruit-set to harvest and statistical relationships were studied. The vineyards presented different climatic and soil conditions which influenced bud burst, shoot growth and plant photosynthesis; concerning soil properties, texture was the main differentiating factor. During the growing season, the berries followed the normal growth pattern, but an extreme drop occurred at harvest due to high diurnal temperatures. Ripening curves showed dissimilarities between the three studied vineyards, i.e. TSS, berry mass, total anthocyanins and total phenols. La Generala presented the best viticulture features regarding the vine performance and grape composition.
\end{abstract}

\section{Introduction}

A terroir can be defined as an agro-ecosystem whose natural attributes - soil, subsoil, relief and climate constitute a unique set of factors that, through plants and animals, give the food product specific characteristics [1]. According to the current and official definition of the OIV, a viticulture terroir is: "A concept which refers to an area in which collective knowledge of the interactions between the identifiable physical and biological environment and applied vitivinicultural practices develops, providing distinctive characteristics for the products originating from this area. "Terroir" includes specific soil, topography, climate, landscape characteristics and biodiversity features" [2]. It can be said that the structural character and potential wine quality is derived from the environment features of the planting site and the wine's personality from the vintage conditions, whilst the final balance and style are shaped by the viticulturist. When these three influences meet in perfect harmony, a great and unique wine will result [3].

Within this perspective, the "zoning" technique initiated, allowing the division of a territory in function of comparable and divergent features of environmental (and human) characteristics and checking the qualitative result of different species and varieties [4]. Viticultural zoning can be defined as the spatial characterization of zones or units that produce grapes or wines of similar performance and composition, while enabling operational decisions to be implemented more effectively [5]. The aims of viticultural zoning are related to the delimitation of protected viticultural areas, which serve to give added value to wines according to their origin and typicality, or the delimitation of homogeneous areas for vineyard management, which can be used to optimize the grape quality [6]. With strong national and international competition, as well as challenging conditions such as a changing climate, studies to determine suitability for the cultivation of grapevines and wine management are becoming more and more widespread [7].

In this context, the trial was carried out in the Bersano estate (Nizza Monferrato, Piemonte, Italy) devoted to the production of Nizza DOCG, the newest and highly reputed Barbera denomination. For Bersano, this research provide access to scientific information and tools to valorise its Nizza wines and to characterize and select some sub-zones. The study investigated the 
effect of natural terroir attributes on Barbera grapevine performance and grape quality.

\section{Material and Methods}

\subsection{Natural environmental features}

The research project considered three vineyard areas, which are namely La Generala, Cremosina and Monteolivo, located in the heart of the Barbera production area (Monferrato, Asti province, Piedmont region), where Bersano winery owns 10 ha devoted to the production of DOCG Nizza wines. The climatic conditions of the three studied areas were characterized by two automatic meteorological stations, one placed near Agliano Terme (covering La Generala area) and the other in Nizza Monferrato (covering La Cremosina and Monteolivo areas). Bioclimatic indices such as the Huglin index and Winkler index were calculated for the growing season of 2017.

The physical and chemical soil properties of the three estates were also determined. The training system for the three areas was simple Guyot with a fruit cane of 7 or 8 buds with a renewal spur (two buds) from the other side to get an average yield of 9 tons per hectare. The following plant material was utilized:

- La Generala: Barbera standard vines, grafted on Rupestris du Lot.

- Cremosina: Barbera clone AT84 grafted on 420 A.

- Monteolivo: Barbera clone AT84 grafted on SO4

\subsection{Vine phenology and growth}

The control of phenological phases was done according to the modified Eichhorn and Lorenz system [8]. The control of phenological stages begun in April and ended with harvest. Starting mid-May, shoot length was measured weekly on two shoots per vine (20 shoots per vineyard) until shoot trimming. When inflorescences were clearly visible (stage 15), the total number of buds and inflorescences per plant were counted and bud fertility determined [9].

Gas exchange readings were performed on 15 vines per vineyard, by checking one leaf/shoot inserted at nodes 7-10. Leaves were sampled on 30 June (fruit set) and 08 August 2017 (veraison). Readings were taken with a ADC BioScientific LCi Analyser Serial No. 31581 within the $10 \mathrm{~h}$ to $13 \mathrm{~h}$ time windows. Two field measurements of greenness index were made with the Soil-Plant Analysis Development SPAD-502 chlorophyll meter throughout the season. The measurements were made on 30 June (fruit set) and 08 August 2017 (veraison) on 1 leave per vine (15 vines per plot), located two nodes above the second cluster on a middle vigorous shoot.

\subsection{Berry growth and ripening}

In order to calculate berry growth (on a weight basis) according to Gray and Coombe [10] a 20-berry sample for each plant tagged (ten per vineyard) was collected, at 10-day intervals beginning from fruit set.

Ripening curves of berry mass, must TSS (Total Soluble Solids), TA (Titratable Acidity) and anthocyanins and phenolics concentrations were calculated in each vineyard [8] at 10-day intervals beginning from veraison, by analyzing a 300-berry sample from each vineyard.

At harvest, (04/09 in Monteolivo, 08/09 in Cremosina and 12/09 in La Generala), yield and cluster number per vine were recorded, mean cluster mass was then calculated. A two basal-cluster sample was collected from each tagged vine. A first 50-berry sample was used for determining total anthocyanins and phenolics concentrations $(\mathrm{mg} / \mathrm{g})$ according to the method reported [9]. A second 20-berry sample was used for identification and quantification of phenolic compounds in grape [10]. The remaining amount of each two-cluster sample was used for individual berry mass assessment and, upon crushing, must was processed for total soluble solids concentration ( ${ }^{\circ}$ Brix), $\mathrm{pH}$ and titratable acidity $(\mathrm{g} / \mathrm{L})$ with standard methods.

\section{Results and Discussion}

\subsection{Influence of climate and soil on vine phenology and growth}

The year 2017 is considered one of the warmest and driest, with a Winkler index of $1988^{\circ} \mathrm{C}$ (Generala) and $1835^{\circ} \mathrm{C}$ (Cremosina and Monteolivo) and a seasonal rainfall of $359.2 \mathrm{~mm}$ (Generala) and $330.6 \mathrm{~mm}$ (Cremosina and Monteolivo), resulting in a phenological earliness of 10 to 20 days. According to the recorded data, Generala vineyards are warmer and wetter than Cremosina and Monteolivo (Figures 1,2).

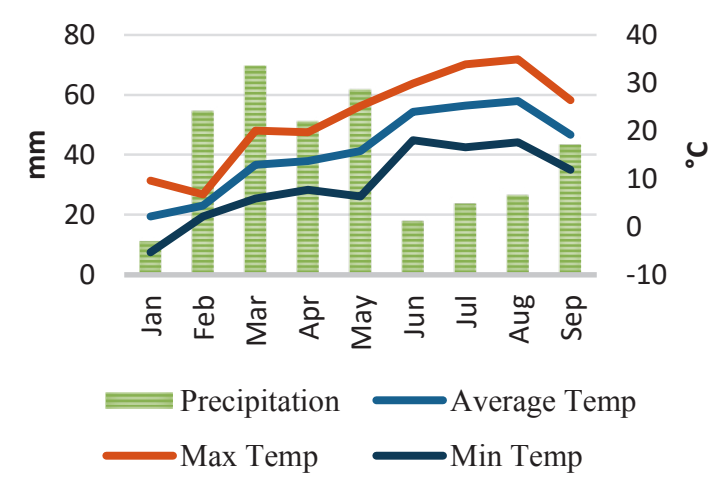

Figure 1. Generala's climate data (1 January to 21 September 2017). Data source: Coldiretti Grower Union.

Except for bud burst, phenological stages occurred at the same time. According to Lee [11], higher temperatures in the latter part of winter anticipate the time of budburst. In March, Generala had a higher average temperature than the other vineyards, resulting in an earlier bud burst in Generala as compared to Cremosina and Monteolivo. 


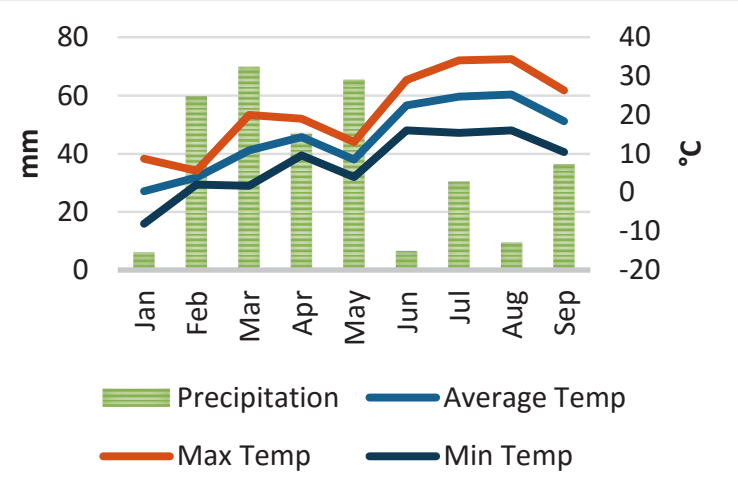

Figure 2. Cremosina and Monteolivo climate data (1 January to 21 September 2017). Data source: Coldiretti Grower Union.

In the three vineyards, the rapid shoot elongation almost stopped at the end of April (132 DOY) (Figure $3)$, due to unexpected low temperatures $\left(-3{ }^{\circ} \mathrm{C}\right.$ in Cremosina and Monteolivo, and $0.2{ }^{\circ} \mathrm{C}$ in Generala), as shoot elongation is positively related to Heat Degree Days (HDD). In addition of this event, the difference in shoot length between Cremosina, Monteolivo and Generala was also due to soil temperature. We can speculate that the lower shoot length recorded in Monteolivo during all the measures is due to its loamy soil, while as Cremosina has less clay and more sand that warms up faster (Figure 4), resulting in a higher shoot length.

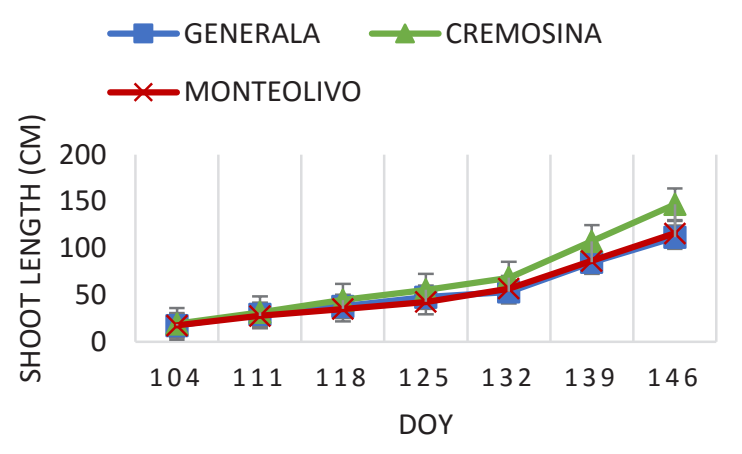

Figure 3. Pre-trimming shoot length measured at weekly intervals from 4 April to 26 May 2017 (DOY 104 to 145 ). Vertical bars indicate standard errors, $n=7$.

Grapevine photosynthesis is affected by environmental factors, one of them is the relative humidity, which stomatal conductance. According to Stoev \& Dobreva [12], an optimal hydrometric is 60 to $70 \%$. During the leaf gas exchange measures (June and July), Cremosina and Monteolivo vineyards had an average relative humidity around $70 \%$ and in the case of Generala it was around $60 \%$. These values compared to the stomatal conductance and photosynthesis data recorded (Table 1) show a positive interaction, the increase in relative air humidity is reflected in the stomatal conductance.

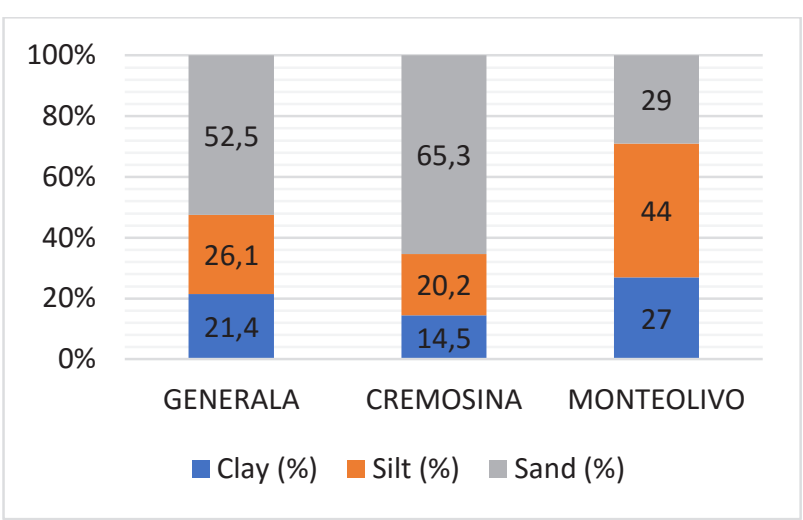

Figure 4. Proportion of sand, silt and clay in Generala, Cremosina and Monteolivo soils. Data source: Coldiretti Grower Union and Impresa Verde Cuneo.

Table 1. Leaf gas exchange measured at pea size (30 June 2017) and veraison (8 July 2017) growth stages.

\begin{tabular}{|c|c|c|c|c|}
\hline Site & \multicolumn{2}{|c|}{ Pea-size } & \multicolumn{2}{|c|}{ Veraison } \\
\hline & $\begin{array}{l}\mathrm{g}_{\mathrm{s}} \\
(\mathrm{mol} / \mathrm{m} \\
2 \cdot \mathrm{s})\end{array}$ & $\begin{array}{l}\mathrm{A} \\
(\mu \mathrm{mol} / \mathrm{m} \\
\left.2^{2} \cdot \mathrm{s}\right)\end{array}$ & $\begin{array}{l}\mathrm{g}_{\mathrm{s}} \\
(\mathrm{mol} / \mathrm{m} \\
2 \cdot \mathrm{s})\end{array}$ & $\begin{array}{l}\mathrm{A} \\
(\mu \mathrm{mol} / \mathrm{m} \\
\left.2^{2} \cdot \mathrm{s}\right)\end{array}$ \\
\hline Generala & 0.07 & 9.20 & 0.12 & 9.73 \\
\hline Cremosina & 0.10 & 11.28 & 0.11 & 10.80 \\
\hline Monteolivo & 0.15 & 12.78 & 0.09 & 8.36 \\
\hline Sig. & ns & ns & ns & n.s \\
\hline
\end{tabular}

*, $\mathrm{P} \leq 0.05$; Within each column, means followed by different letters are significantly different $(\mathrm{P}<0.05)$ according to the Student-Newman-Keuls test. ns, not significant. (gs) Stomatal conductance (A) Photosynthesis rate.

\subsection{Influence of climate and soil on berry growth and ripening}

During the growing season of 2017, the berries in the three vineyards followed the normal growth pattern, according to a double sigmoidal curve [8]. However, an extreme drop at the harvest occurred (Figure 5) due to higher temperatures $\left(>40^{\circ} \mathrm{C}\right)$ and lack of rain which caused the dehydration of the grapes.

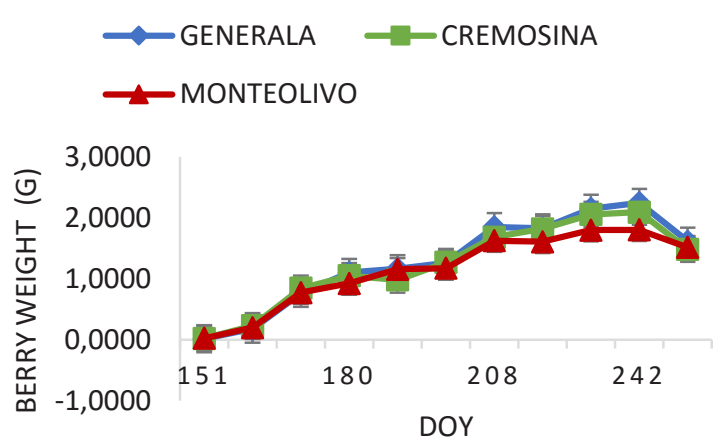

Figure 5. Berry growth measured at intervals of 10 days within the day of the year (doy) 151-harvest period (31 May to 4, 8 and 14 September) in 2017. Vertical bars indicate standard error, $\mathrm{n}=11$ 
Among the different parameters (Figure 6), four of them showed differences between the three vineyards (TSS, berry mass, total anthocyanins and total phenols). Also Carlomagno et al. [13] demonstrated a role of the location on Barbera volatiles during ripening.
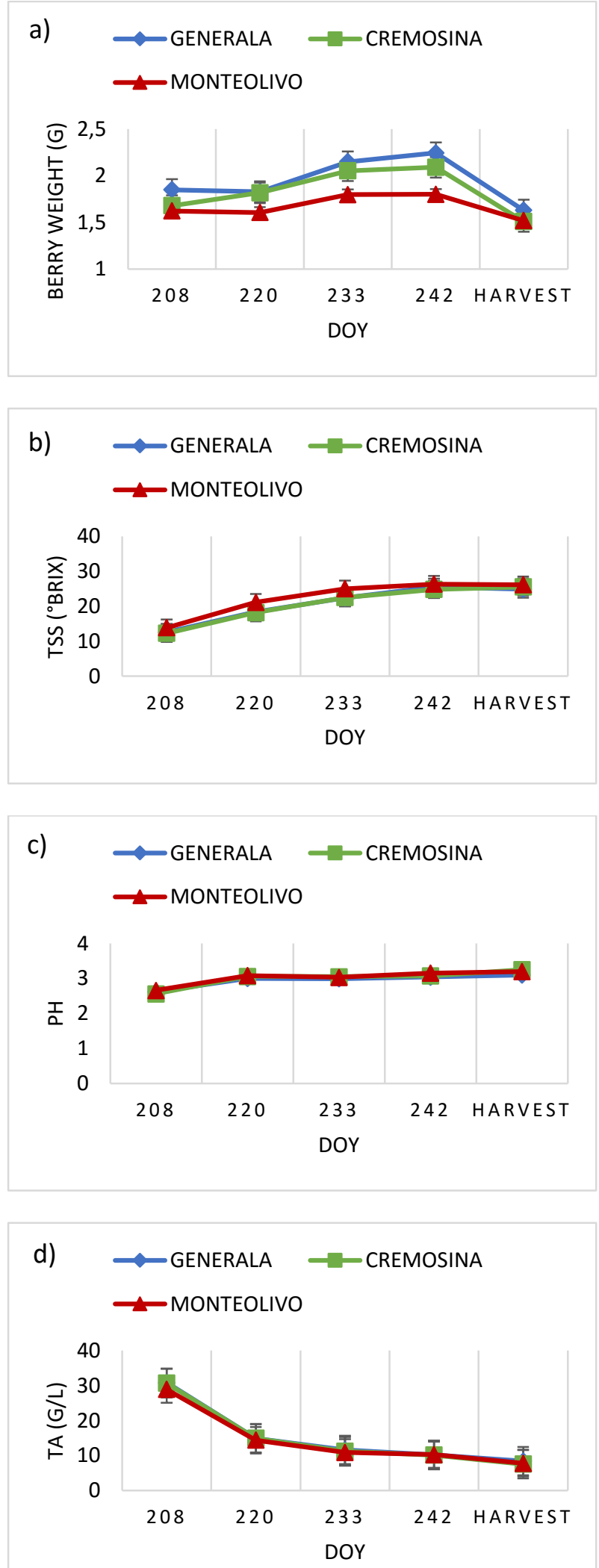
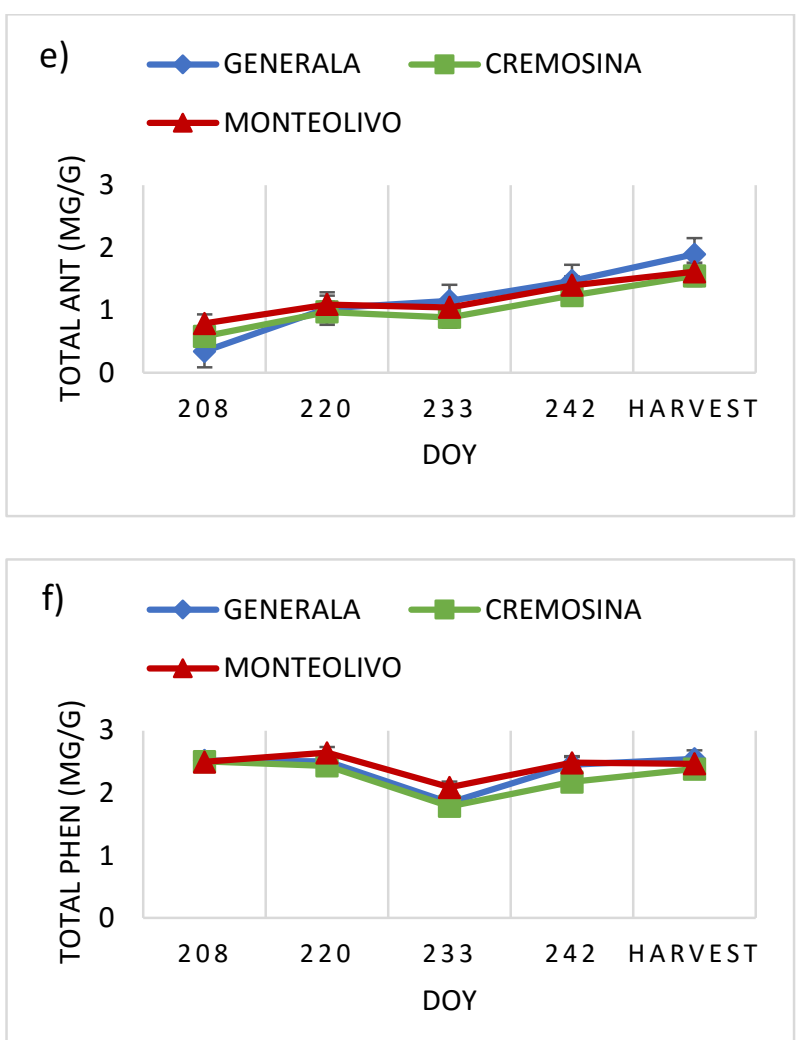

Figure 6. Growth and ripening curves for (a) berry weight, (b) TSS, (c) pH, (d) total acidity, (e) total anthocyanins and (f) total phenols of Barbera grapes. Vertical bars indicate standard error, $\mathrm{n}=5$; day of the year (DOY).

In addition to climatic conditions, soil has a strong influence on grape composition during ripening, as being the main water resource for the plant, and soil moisture-holding capacity is related to the soil texture. The effect of water deficit correlates with the decrease in the size of berries and changes in the ratio between skin and berry weight, which in turn affects the concentration of phenolic compounds [15]. These principles explain the rapid concentration of total anthocyanins and phenols from the 233 DOY till harvest (Figures 6e and 6f), period in which there was a combination of lack of rain and high average temperatures that reached $34.5^{\circ} \mathrm{C}$ (Generala) and $34.4^{\circ} \mathrm{C}$ (Cremosina and Monteolivo).

\subsection{Grape quality and vine performance at harvest}

There was no significant difference in almost all the parameters of vine performance and grape composition. Generala presented higher concentrations of total anthocyanins $(1.90 \mathrm{mg} / \mathrm{g})$ and total phenolics (2.55 $\mathrm{mg} / \mathrm{g})$ than Cremosina (1.55 mg/g and $2.39 \mathrm{mg} / \mathrm{g})$ and Monteolivo (1.62 mg/g and $2.49 \mathrm{mg} / \mathrm{g}$ ) (Table 2). However, the three vineyards presented better levels of berry anthocyanins in comparison to the general average levels recorded by Regione Piemonte during the last years across the region [14]. 
Table 2. Grape composition at 2017 harvest in Generala, Cremosina and Monteolivo vineyards.

\begin{tabular}{lllll} 
Vineyard & $\begin{array}{l}\text { TSS } \\
\left({ }^{\circ} \text { Brix) }\right.\end{array}$ & $\begin{array}{l}\text { TA } \\
(\mathbf{g} / \mathbf{L})\end{array}$ & $\begin{array}{l}\text { Total } \\
\text { Ant } \\
(\mathbf{m g} / \mathbf{g})\end{array}$ & $\begin{array}{l}\text { Total } \\
\text { Phen } \\
(\mathbf{m g} / \mathbf{g})\end{array}$ \\
\hline Generala & 24.9 & 8.4 & 1.90 & 2.55 \\
\hline Cremosina & 25.5 & 7.6 & 1.55 & 2.39 \\
\hline Monteolivo & 26.1 & 7.8 & 1.62 & 2.49 \\
\hline Sig & n.s. & n.s. & n.s. & n.s.
\end{tabular}

*, P $\leq 0.05$; Within each column, means followed by different letters are significantly different $(\mathrm{P}<0.05)$ according to the Student-Newman- Keuls test. ns, not significant.

\section{Conclusions}

The effectiveness of the results achieved lies in the methodology applied on the same grape variety (vitis vinifera L cv. Barbera) and under the same cultural practices (except for the clone and rootstock). We believe that, under these conditions, the viticulture profiles reported represent a very good approach to vineyard potentialities. The three tested vineyards have the following viticulture profile:

Generala: sandy-clay-loamy soils, alkaline, medium levels of total nitrogen and organic matter, annual growing cycle of 167 days (31 March-14 September), with a seasonal rainfall of $359.2 \mathrm{~mm}$ and heat accumulation of 1998 GDD (growing degree days); it is listed under the region IV in the Winkler scale. Due to its climate and soil characteristics, it presents an excellent concentration of total anthocyanins (1.90 $\mathrm{mg} / \mathrm{g}$ ) and phenolics $(2.55 \mathrm{mg} / \mathrm{g})$.

Cremosina: sandy-loamy soil, alkaline, with poor levels of total nitrogen and organic matter, annual growing cycle of 159 days (2 April-8 September) with a seasonal rainfall of $331 \mathrm{~mm}$ and heat accumulation of 1835 GDD (growing degree days); it is listed under the region III in the Winkler scale. Due to its climate and soil characteristics, it presents good levels of total anthocyanins $(1.55 \mathrm{mg} / \mathrm{g})$ and total phenolics (2.39 $\mathrm{mg} / \mathrm{g}$ ).

Monteolivo: loamy soil, alkaline, with poor levels of total nitrogen and organic matter, annual growing cycle of 155 days (2 April-4 September) with a seasonal rainfall of $331 \mathrm{~mm}$ and heat accumulation of 1835 GDD (growing degree days); it is listed under the region III in the Winkler scale. Due to its climate and soil characteristics, it present good levels of total anthocyanins $(1.62 \mathrm{mg} / \mathrm{g})$ and total phenolics (2.49 $\mathrm{mg} / \mathrm{g}$ ).

The three terroirs studied and classified as Nizza DOCG present differences in the vegetative growth, vine performance and grape quality related to the variation in the main terroir environmental factors (soil properties and meteorological conditions). On the basis of the results, we can conclude that Generala terroir in comparison with Cremosina and Monteolivo, presented the best viticulture features regarding the vine performance and grape composition. However, the interaction of the three terroirs with the variety needs to be deepened by further research, as well as correlation with wines (chemical and sensory profile). This study is the first step for Bersano winery to characterize its three terroirs inside Nizza DOCG.

\section{References}

1. C. Van Leeuwen, \& G. Seguin, J Wine Res. The Concept of Terroir in Viticulture, 17, 1-10 (2006)

2. OIV, Resolution OIV/Viti 333/2010, Definition of vitivinicultural "Terroir" (2010)

3. M. Fregoni, Phytoline, Terroir, zonazione, viticoltura, (2003)

4. E. Constantini, R. Barbetti, P. Bucelli, A. Cimato, E. Franchini, G. L'Abate, \& P. Storchi, Zonazione viticola ed olivicola della provincia di Siena. Colle val d'Elsa, 224 (2006)

5. E. Vaudour, Les terroirs viticoles. Définitions, caractérisation, protection, (2003)

6. E. Vaudour \& A. Shaw, SAJEV, Worldwide Perspective on Viticultural Zoning, 26(2), 106-115 (2005)

7. E. Vaudour, E. Costantini, G.V. Jones, S. Mocali. An overview of the recent approaches to terroir functional modelling, footprinting and zoning. Soil 1, 287-312 (2015)

8. D. Lorenz, K. Eichorn, H. Bleiholder, R. Klose, U. Meier \& E. Weber, Aust. J. Grape Wine Res., Phenological growth stages of the grapevine (Vitis vinifera L. spp. vinifera). Codes and descriptions according to the extended $B B C H$ scale, 1, 100-103 (1995)

9. P. Iland, P. Dry, T. Proffitt \& S. Tyerman, The Grapevine from the science to the practice of growing vines for wine, 32-62 (2011)

10. J. Gray \& B.G. Coombe, Aust. J. Grape Wine Res. Variation in Shiraz berry size originates before fruitset but harvest is a point of resynchronisation for berry development after flowering, 15, 156-165 (2009)

11. I. Lee, \& B. Coombe, Viticulture, 2, 150-166 (2004) 12. K. Stoev \& S. Dobreva, Connaisance de la vigne et $d u$ vin, 2(10), 125-139 (1976)

13. A. Carlomagno, A. Schubert \& A. Ferrandino, Volatiles in Vitis vinifera L. cv Barbera during ripening as influenced by growing location. IXe Congrès International des Terroirs vitivinicoles 7, 29-32 (2012)

14. Regione Piemonte, BARBERA Studio per la caratterizzazione del territorio, delle uve e dei vini dell'area di produzione del barbera d'Asti, (2001) 